\title{
Ileo-colic intussusception by ileo-cecal valve lipoma - an infrequent ultrasonographic occurrence. A case report.
}

\section{Bogdan Stancu ${ }^{*}$, Alexandra Chira ${ }^{2 *}$, Romeo Ioan Chira ${ }^{3}$, Ioana Grigorescu ${ }^{2}$, Claudia Diana Gherman $^{4}$, Dan Lucian Dumitraşcu ${ }^{2}$}

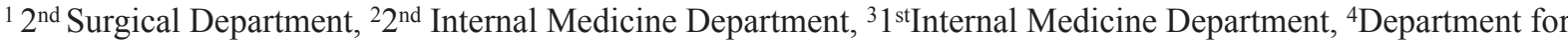 \\ Clinical Abilities, "Iuliu Hatieganu" University of Medicine and Pharmacy Cluj-Napoca, Romania \\ * the authors shared the first authorship
}

\begin{abstract}
We present a rare cause of intestinal obstruction in an adult, due to ileo-colic intussusception by a lipoma of the ileo-cecal valve and its ultrasonographic presentation. The case presented in emergency for spontaneously appearing and disappearing palpable elastic mass in the right iliac fossa. The ultrasonographic examination raised the suspicion of an ileo-colic intussusception due to a polypoid tumor. The contrast-enhanced computed tomography confirmed the finding and suggested that the polypoid tumor was more likely a lipoma. Right hemicolectomy and cholecystectomy were performed and the pathological examination confirmed the lipoma. The evolution of the patient was favourable and uneventful.
\end{abstract}

Keywords: intestinal lipoma, intussusception, ultrasonography, computed tomography, hemicolectomy

\section{Introduction}

Intussusception, defined as the telescoping of one segment of the intestine within another, is a relatively rare condition in adults compared with children. It accounts for $5 \%$ of all cases of intussusceptions, and $1-3 \%$ of etiologic factors for bowel obstructions [1]. More than $90 \%$ of patients with adult intussusception have organic causes, mainly benign (polyps, Meckel's or colonic diverticulum, or strictures) or malignant, pathologies that are usually intraoperatively discovered [2].

Lipomas, the most common benign mesenchymal tumors found in the gastrointestinal tract, are located in the distal ileum and colorectal region (mainly the right

Received 29.10.2015 Accepted 30.11.2015

Med Ultrason

2016, Vol. 18, No 3, 394-396

Corresponding author: Claudia Diana Gherman, MD

Department for Clinical Abilities, Iuliu Hatieganu" University of Medicine and Pharmacy Cluj-Napoca

223 Gh. Marinescu str

400006 Cluj-Napoca, Romania

E-mail: ghermanclaudia@yahoo.com colon). Intestinal lipomas seldom deteriorate, being complicated with intestinal obstruction or haemorrhage, and do not relapse after cure [3]. The manifestations of symptomatic lipoma include abdominal pain, hemorrhage, or incomplete intestinal obstruction. Because of their intramural location, lipomas can also serve as the leading point for intussusceptions [4].

Preoperative diagnosis of etiology of intussusceptions remains difficult, in approximately $50 \%$ of the cases the diagnosis being established intraoperatively [5]. Computed tomography (CT) and ultrasonographic (US) examination can be used and typical "sausage-like" or "target-like" images can be seen [6].

We present a case of symptomatic ileo-cecal valve lipoma which caused ileo-colic intussusception and required surgery, underlining the US and CT findings of this tumor

\section{Case report}

A 52 year old female was admitted presenting in the last month abdominal pain in the right iliac fossa and left flank, $5 \mathrm{~kg}$ weight loss, and constipation. Routine labo- 
ratory investigations were in normal range. The patient was afebrile and hemodynamically stable. At admission an elastic mass was palpable in the right iliac fossa, but the next day the patient become asymptomatic the mass was not retrieved. Two days after the pain reappeared as well as the elastic mass, but this time it was located in the right periumbilical area with absence of intestinal transit and later clinical signs of intestinal obstruction.

The US examination found a typical „bulls-eye” or „doughnut" shaped mass on the short axis view, including a hyperechoic, spheric tumour in continuity with a laminary structure with layers of different echogenicities. With the linear transducer hyperechoic, homogenous tumour covered by the intestinal wall with a minimal peritumoral fluid| was found (fig 1a-b). US examination raised the suspicion of ileo-colic intussusception, probably due to a polyploidy tumor.

The contrast-enhanced CT described $14 \mathrm{~cm}$ ileocolic intussusception until the proximal transverse colon, which presented on the medial extremity a $4.1 / 3.2 \mathrm{~cm}$ fatty mass which could be an ileo-cecal valve lipoma. CT also described a marked edema of the colonic wall at this level and a slightly adjacent fat infiltration. There were no signs of perforation, pneumoperitoneum, intraabdominal liquid or bowel distension upstream of the intussusception (fig 1c-d).

With the diagnosis of ileo-colic intussusception, the patient underwent urgent surgery. A laparotomy was performed revealing an ileo-colic intussusception extended from the ileum to the ascending colon, due to a polypoid mass located in the terminal ileum (fig 1e). The intussusception was not reduced, given the suspicion of a malignant process and right hemicolectomy with side-to-side anastomosis of the ileum and the transverse colon was performed. The patient was discharged complication-free seven days after surgery. The histopathological exam revealed a $5.5 / 5.5 \mathrm{~cm}$ cecal submucosal lipoma on the ileo-cecal valve. No evidence of dysplasia or malignancy was found.

\section{Discussions}

Ileo-colic intussusception represents $15 \%$ of all intussusceptions and it is a common complication of intestinal lipomas. Lipomas account for 5\% of all gastrointestinal tumors [7]. Small lipomas are usually asymptomatic and only rarely detected in colonoscopy or surgery. Lipomas $>2 \mathrm{~cm}$ diameter may produce abdominal pain, obstruction or intussusceptions [8]. US is usually the first diagnostic modality chosen, especially when the lipoma is accompanied by intestinal intussusception. Classic features are a "doughnut sign" or "pseudo- kidney", but image interpretation can be difficult in the presence of air [9]. The characteristic US finding associated with an intussusception is the "target sign", in which the outermost layer represents the sheath, and the multilayer ring structure represents the invaginated intestinal segment [10]. In some cases, US can show a suborbicular nested mass with a clear boundary, low blood supply, and strong ultrasonic echo. If color flow Doppler is used, the presence of bowel necrosis may be demonstrated by showing compromised blood flow to the intussusceptum. The major disadvantage of ultrasound is masking by gas-filled loops of bowel, and operator dependency [11]. However, US is generally limited to the demonstration of intestinal dilation and obstruction [12].

US is quick and cost-effective and shows, when performed by an experienced physician, similar sensitivity and specificity such as CT [13]. US is a readily available and a more generalized technique than $\mathrm{CT}$, enabling it to be used more often with emergency and acute symptoms and thus being available at times of abdominal crisis in intermittent processes $[14,15]$.US allows a study on all planes and in real time, which is important as intussusception is often a dynamic phenomenon [16].

The preoperative diagnostic accuracy of US is $78.5 \%$. In cases of palpable abdominal mass, the diagnostic accuracy of US is even better $86.6 \%$ [17].

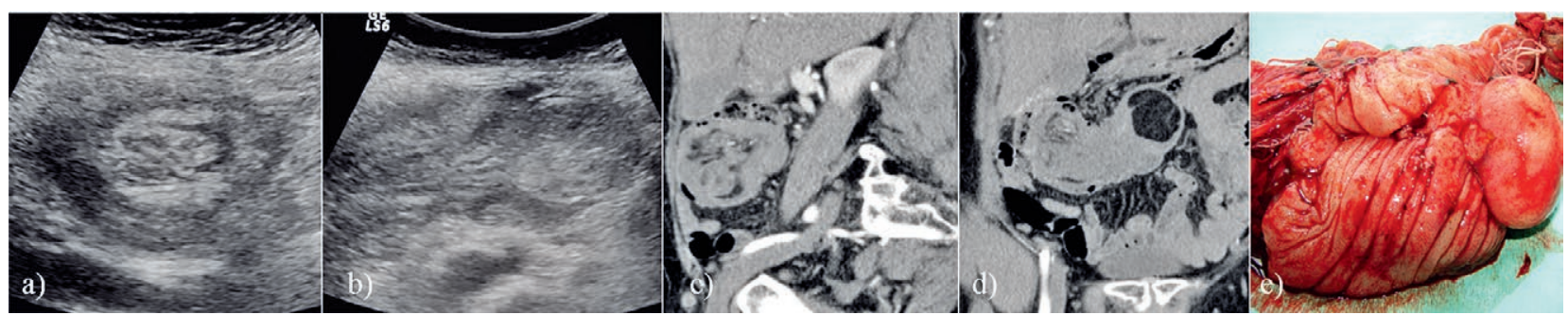

Fig 1. a) Ultrasonography, short axis view with typical "bulls-eye" or "doughnut" shaped mass of the concentric rings corresponding to intussusception; b) Ultrasonography: hyperechoic, spheric tumour in continuity with a laminary structure with layers of different echogenicities - intussucepted ileocolic segment with the tumour; c) Contrast-enhanced CT scan, sagital section representing the intussuception; d) Contrast-enhanced CT scan, coronal section representing the intussucepion and the leading point - a fatty mass, probably a lipoma, with oedema at this level; e) Postsurgical aspect of the terminal ileum and ascending colon, with the leading point of ileocecal intussusception - the lipoma. 
$\mathrm{CT}$ is the most valuable diagnostic method for intestinal intussusception, and it can clearly reveal the typical characteristics of uniform tumor density, a clear border, no reinforcement, and fat (negative) density, allowing for a definite diagnosis [18]. CT has a sensitivity of $58-100 \%$ and a specificity of $57-71 \%$ in determining the etiology; a "target sign" or a "sausage shaped" mass with different layers of attenuation can be shown in CT [17,19].

$\mathrm{CT}$ is excellent in revealing the site, level, and cause of intestinal obstructions and in indicating possible bowel ischemia. It can give additional information, such as metastasis or lymphadenopathy, which may indicate an underlying pathology [20,21].

The particularity of this case is that symptomatic intussusception is rare in adults, and also ileo-cecal valve lipoma is rarely the cause. The initial diagnosis was established using US while most of the cases presented in the literature are using CT per primam.

\section{Conclusions}

Adult bowel intussusception is a rare cause of intestinal obstruction and a challenging condition for the surgeon. Preoperative diagnosis is often missed or delayed because of non-specific symptoms. CT is the preferred diagnostic method for this rare, benign condition, because it clearly demonstrates the presence and location of intussusception and it can differentiate fat tissue from other tissues. US is quick and cost-effective and shows, when performed by an experienced physician, similar sensitivity and specificity such as $\mathrm{CT}$, when the ileo-cecal valve lipoma is accompanied by intestinal intussusception.

Acknowledgement: Part of this paper was presented at CEURGEM 2014 (Gdansk) - poster section and awarded the $3^{\text {rd }}$ Prize.

\section{References}

1. Ghrissi R, Belhajkhlifa MH, Elghali MA, Saleh Jarrar MS, Hamila F, Letaief MR. Acute intussusception on a lipoma of the left colon: report of a case. J Biomed Graph Comput 2016; 6: 20-22.

2. Onkendi EO, Grotz TE, Murray JA, Donohue JH. Adult intussusception in the last 25 years of modern imaging: is surgery still indicated? J Gastrointest Surg 2011; 15: 16991705.

3. Balamoun H, Doughan S. Ileal lipoma - a rare cause of ileocolic intussusception in adults: case report and literature review. World J Gastrointest Surg 2011; 3: 13-15.

4. Vagholkar K, Chavan R, Mahadik A, Maurya I. Lipoma of the small intestine: a cause for intussusception in adults. Case Rep Surg 2015; 2015: 856030.
5. Chehade HH, Zbibo RH, Nasreddine W, Abtar HK. Large ileocecal submucosal lipoma presenting as hematochezia, a case report and review of literature. Int J Surg Case Rep 2015; 10: 1-4.

6. Gys B, Haenen F, Gys T. Ileocolic intussusception caused by a giant ulcerating lipoma of Bauhin's valve: an unusual cause of intestinal obstruction in the adult. Indian $\mathrm{J}$ Surg 2015; 77(Suppl 1): 1-2.

7. Vekić B, Živić R. Pedunculated obstructive lipoma of the ileocecal valve: a case report. Srp Arh Celok Lek 2014; 142: 721-723.

8. Grasso E, Guastella T. Giant submucosal lipoma cause colo-colonic intussusception. A case report and review of literature. Ann Ital Chir 2012; 83: 559-562.

9. Lindor RA, Bellolio MF, Sadosty AT, Earnest F 4th, Cabrera D. Adult intussusception: presentation, management, and outcomes of 148 patients. J Emerg Med 2012; 43: 1-6.

10. Jiang RD, Zhi XT, Zhang B, Chen ZQ, Li T. Submucosal Lipoma: a rare cause of recurrent intestinal obstruction and intestinal intussusception. J Gastrointest Surg 2015; 19: 1733-1735.

11. Seow-En I, Foo FJ, Tang CL. Jejunojejunal intussusception secondary to submucosal lipoma resulting in a 5-year history of intermittent abdominal pain. BMJ Case Rep 2014 Oct 29. doi: 10.1136/bcr-2014-207297.

12. Eyselbergs M, Ceulemans LJ, De Bontridder S, et al. Ileocolic intussusception due to lipomatosis of the ileum: a common complication of a rare clinical entity. JBRBTR 2014; 97: 36-38.

13. Martín-Lorenzo JG, Torralba-Martinez A, Lirón-Ruiz A, et al. Intestinal invagination in adults: preoperative diagnosis and management. Int J Colorectal Dis 2004; 19: 68-72.

14. Kumar L, Lakshman TK. Giant submucosal lipomatous polyp causing perforation of sigmoid colon: a case report and review of literature. J Clin Diagn Res 2015; 9: PD22-PD24.

15. Mostafa HA, Saad J, Hassan A, Zafar N. Adult intussusception. An overlooked diagnosis in the emergency department. Saudi Med J 2014; 35: 285-291.

16. Bosman WM, Veger HT, Hedeman Joosten P, Ritchie ED. Ileocaecal intussusception due to submucosal lipoma in a pregnant woman. BMJ Case Rep 2014 Feb 14. doi: 10.1136/bcr-2013-203110.

17. Singhal S, Singhal A, Arora PK, et al. Adult ileo-ileo-caecal intussusception: case report and literature review. Case Rep Surg 2012; 2012: 789378.

18. Moussa OM, Tee M, Khan AU, Selvasekar CR. Computerized tomography providing definitive diagnosis of colonic lipoma: a case series. Surg Laparosc Endosc Percutan Tech 2013; 23: e232-e234.

19. Lianos G, Xeropotamos N, Bali C, Baltogiannis G, Ignatiadou E. Adult bowel intussusception: presentation, location, etiology, diagnosis and treatment. G Chir 2013; 34: 280-283.

20. Parlak S, Okay AE, Altin L, Toprak U, Kuscuoglu G, Karademir MA. Lipomatosis of terminal ileum and ileocecal valve: multidetector computed tomography findings. Iran J Radiol 2014; 11: e4336.

21. Esnakula AK, Sinha A, Fidelia-Lambert M, Tammana VS. Angiolipoma: rare cause of adult ileoileal intussusception. BMJ Case Rep 2013 Mar 26. doi: 10.1136/bcr-2013-008921. 